Original Research Paper

\title{
Experimental Investigation on CRDI System Assisted Diesel Engine Fulled by Diesel with Nanotubes
}

\author{
C. Syed Aalam, C.G. Saravanan and M. Kannan \\ Department of Mechanical Engineering, Annamalai University, Annamalainagar, Tamilnadu, India
}

Article history

Received: 15-03-2015

Revised: 01-05-2015

Accepted: 25-05-2015

Corresponding Author:

C. Syed Aalam

Department of Mechanical

Engineering, Annamalai

University, Annamalainagar,

Tamilnadu, India

Email:syedaalam3386@gmail.com

\begin{abstract}
This paper reports on the use of carbon multiwalled nanotubes as additive to the diesel fuel and the effects of their operational characteristics and performance, emission and combustion characteristics of the CRDI system assisted diesel engine. In this study, the tested fuels were prepared by dispersing carbon multiwalled nanotubes into the diesel fuel at the mass fraction of 25 and $50 \mathrm{ppm}$ with the help of a mechanical homogenizer and an ultrasonicator. Experimental results showed that the flash points and cetane number of the fuels dispersed with carbon multiwalled nanotubes have increased with higher concentration of carbon multiwalled nanotubes. Based on the experimental results, $\mathrm{NO}_{x}$ emissions and smoke noticeably decrease, while $\mathrm{CO}$ emissions dramatically increase with increasing the dosing level of carbon multiwalled nanotubes. At the full load, the magnitude of $\mathrm{NO}_{x}$ and smoke emission for the neat diesel was $1282 \mathrm{ppm}$ and $69 \mathrm{HSU}$, whereas it was $910 \mathrm{ppm}$ and $49 \mathrm{HSU}$ for the CMNT50 fuel, respectively. The results also showed a significant enhancement in brake thermal efficiency and heat release rate due to the influence of the carbon multiwalled nanotubes addition in diesel blend.
\end{abstract}

Keywords: Nanotubes, CRDI Diesel Engine, Combustion, Emissions

\section{Introduction}

The increase in energy demand has focussed researchers to find the best way of using conventional energy. Therefore, improvement of fuels is an important issue. The increasing usage of this fossil fuel has a degrading effect on the environment through its polluting combustion product. The recent advances in nano science and nanotechnology proved that the nano energetic materials have great advantages over micro sized materials. Ignition delay and ignition temperatures are the significant parameters to characterize the performance of a diesel engine. Tyagi et al. (2008) made an attempt to improve the ignition properties of diesel fuel by addition of aluminium and aluminium oxide nanoparticles to diesel. It was observed that in all the cases the ignition probability for the diesel-nanoparticles mixture was higher than that of pure diesel. Tajudeen and Velraj (2014) conducted experiments on cerium oxide nanoparticles with diesel, the results showed reduction in ignition delay, higher cylinder peak pressure and higher heat release at higher loads in the case of cerium oxide fuel blend compared to neat diesel. Kumar and Sharma (2014) studied the effect of addition of nanoparticles with neat diesel. From the results, nanomaterials can act as a burning rate catalyst because when dispersed into liquids they accelerate the burning rate and promote clean burning, also particulate matters and carbon monoxide are reduced. Arul Mozhi et al. (2009) investigated the performance and emission characteristics of a diesel engine using cerium oxide nanoparticles as an additive in diesel and diesel biodiesel-ethanol blends. They concluded that cerium oxide nanoparticle additive acts as an oxygendonating catalyst and their results revealed that the cerium oxide additive improved the complete combustion of the fuel and exhibited high catalytic activity due to their high surface area per unit volume, which leads to improved fuel efficiency. Karthikeyan et al. (2014) found that the combustion characteristics improved by the lighter surface to volume ratio of nanoparticles, which allowed most amount of fuel to react with the air. It leads to enhance the brake thermal efficiency. By and large, it is observed that the minimum $\mathrm{CO}$ and $\mathrm{HC}$ were measured with the use of $\mathrm{ZnO}$ blend. Fangsuwannarak and Triratanasirichai (2013) conducted experiments on the addition of $\mathrm{TiO}_{2}$ nanoparticles with biodiesel in diesel engine. The addition of $\mathrm{TiO}_{2}$ enhances higher carbon combustion activation and hence promoting complete combustion. Due to complete 
combustion of fuel, emissions like $\mathrm{CO}, \mathrm{CO}_{2}$ and $\mathrm{NO}_{x}$ are appreciably reduced. Basha and Anand (2014) experimentally investigated the performance and the emission characteristics of a diesel engine using Carbon Nanoparticles (CNT) blended diesel. They observed a substantial enhancement in the brake thermal efficiency and reduced harmful pollutants compared to that of neat diesel. This is assumed to be due to better combustion. The same team has critically reviewed the applications of nanoparticles in diesel engines and concluded that adding a suitable proportion of nanoparticles to the conventional fuels such as diesel will reduce the evaporation time, which in turn favors shorter ignition delay.

It is observed from the literature that the combustion behavior of diesel with the addition of nanoscale energetic materials as fuel additives enhance the combustion and engine performance in a diesel engine. In addition, due to the small scale of nanoparticles, the stability of the fuel suspensions should be markedly improved. The changes in diesel fuel properties like viscosity, flash point and fire point, due to the introduction of carbon multiwalled nanotubes additive were observed. The diesel fuel with carbon multiwalled nanotubes additive presented a marginal increase in performance. In the present work, the combustion and engine performance characteristics of a single cylinder diesel engine fuelled with the modified fuel blends, diesel with 25 and 50 ppm CMNT, were tested and the results are compared with the neat diesel.

\section{Carbon Multiwalled Nanotubes}

CNTs can be divided into two types: Single-Walled Carbon Nanotubes (SWNTs) and Multiwalled Carbon Nanotubes (MWNTs). SWNTs consist of a seamless graphene sheet rolled up into a cylinder of a few nanometers in diameter and several microns in length. Most of them are aligned and packed together to form ropes of 10-100 parallel tubes. A MWNT is an arrangement of several, up to tens and hundreds of concentric tubes of graphite sheet with adjacent shells separation of $0.34 \mathrm{~nm}$ on each tube, the carbon atoms are arranged in a helical fashion along the tube axis. The outer diameter of these MWNT is about several tens of nanometers and they have a length of 10-100 nm (Orinakova and Orinak, 2011; Popov, 2004; Hirscher et al., 2002). CNTs can be synthesized by various methods such as arc discharge, laser vaporization and chemical vapor deposition. The first two methods can produce high quality nanotubes. However, the disadvantage is the high temperature or complicated device required, which limits scaling up of their applications. In contrast, chemical vapor deposition is one of the most promising methods for large scale production of graphite fibers and Multiwalled Carbon Nanotubes (MWCNTs). Chemical vapor deposition method has the advantage to produce high purity CNTs with fewer by products and have a low synthesis temperature (Bahgat et al., 2011; Paradise and Goswami, 2007). Carbon nanotubes are unique nanostructures which are known to have remarkable mechanical properties. These characteristics have sparked great interest in their possible uses for nano mechanical devices. Properties of carbon nanotubes can also be expanded to thermal and optical properties as well. Carbon nanotubes are predicted to have high stiffness and axial strength as a result of the carboncarbon $\mathrm{sp}^{2}$ bonding (Ruoff and Lorents, 1995).

\section{Preparation of Fuel Blend}

For the blending of carbon multiwalled nanotubes in diesel, first we take a sample of diesel say 1 litre and then $0.025 \mathrm{~g}$ of carbon multiwalled nanotubes is added to make the dosing level of $25 \mathrm{ppm}$. Subsequently, to increase the dosing level of $50 \mathrm{ppm}$, we have to increase to $0.05 \mathrm{~g} \mathrm{~L}^{-1}$. After the addition of carbon multiwalled nanotubes, it is shaken well. And then it is poured into signification apparatus where it is agitated for about 45 min in an ultrasonic shaker making uniform suspension. It is of colloidal type. It should be shaken well before use, as excess of nanoparticles settle down on solution. The important physical and chemical properties of diesel and CMNT-blended diesel were determined by standard methods (Table 1).

\section{Properties of Carbon Multiwalled Nanotubes}

Scanning electron microscopy provides direct examination of nanotube alignment and size (Cao et al., 2001). The morphology of nanoparticles was investigated by Scanning Electron Microscopy (SEM). The SEM images showed that most of the nanoparticles obtained from all the ablated laser energies have spherical shape with a particle size of less than $100 \mathrm{~nm}$. Furthermore, it was observed that the particle size increased with increasing the laser energy (Piriyawong et al., 2012). SEM of carbon multiwalled nanotubes is shown in Fig. 1. Surface and morphological characterization of carbon multiwalled nanotubes were carried out using scanning electron microscopy. Nanosized spherical shaped carbon multiwalled nanotubes obtained were confirmed. The diameter distribution of the particles varies from 2 to $50 \mathrm{~nm}$.

The nanotube samples usually consist of nanotubes of different radius and chirality. The Raman spectrum contains information about the nanotubes diameters and chirality. This determines the role of the resonant Raman spectroscopy as an important tool for the structural characterization of the nanotubes (Popov, 2004). Figure 2 gives the Radial Breathing Mode (RBM) of CMNTs, which shows the groups of vibration modes among which $126.3,182.5$ and $209.1 \mathrm{~cm}^{-1}$ might be considered from outer layer vibration. The $\mathrm{G}$ band in the 1500- 
$1605 \mathrm{~cm}^{-1}$ range can be used to analyze CMNTs, according to a recent report ( $\mathrm{Li}$ et al., 2005) and it characteristically shows two dominant features, the lower frequency component associated with vibration along the circumferential direction $\left(\mathrm{G}^{-}\right)$and the higher frequency component $\left(\mathrm{G}^{+}\right)$attributed to vibration along the direction of the nanotube axis. After curve fitting, it was found that the $G$ band observed in our CMNTs includes three peaks, which correspond to $\mathrm{G}^{-}$inner, $\mathrm{G}^{-}$ outer and $\mathrm{G}^{+}$(Fig. 2). Splitting of the G band in MWNTs is both small in intensity and smeared out due to the effect of the diameter distribution within the individual MWNTs and because of the variation between different tubes in an ensemble of MWNTs in typical experimental samples. Therefore, the $\mathrm{G}^{-}$band feature predominantly exhibits a weakly asymmetric characteristic lineshape (Dresselhaus et al., 2005).

\section{Experimental Setup and Test Procedure}

Experiments were conducted on Kirloskar AV1, four stroke, single cylinder and air cooled diesel engine assisted by common rail direct injection system. The rated power of the engine was $5.2 \mathrm{~kW}$. The engine was operated at a constant speed of $1500 \mathrm{rpm}$ and a standard injection pressure of 220 bar. The engine was initially fuelled with diesel fuel to provide the baseline data and then, it was fuelled with diesel and carbon multiwalled nanoparticles blended fuel in two different proportions. Details of the engine specification are given in Table 2.

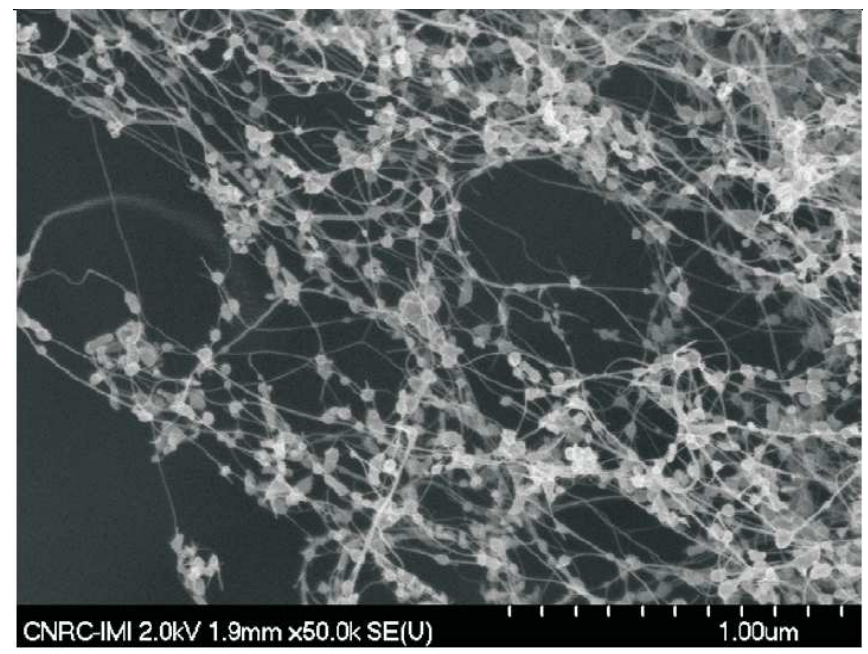

Fig. 1. SEM of carbon multiwalled nanotubes

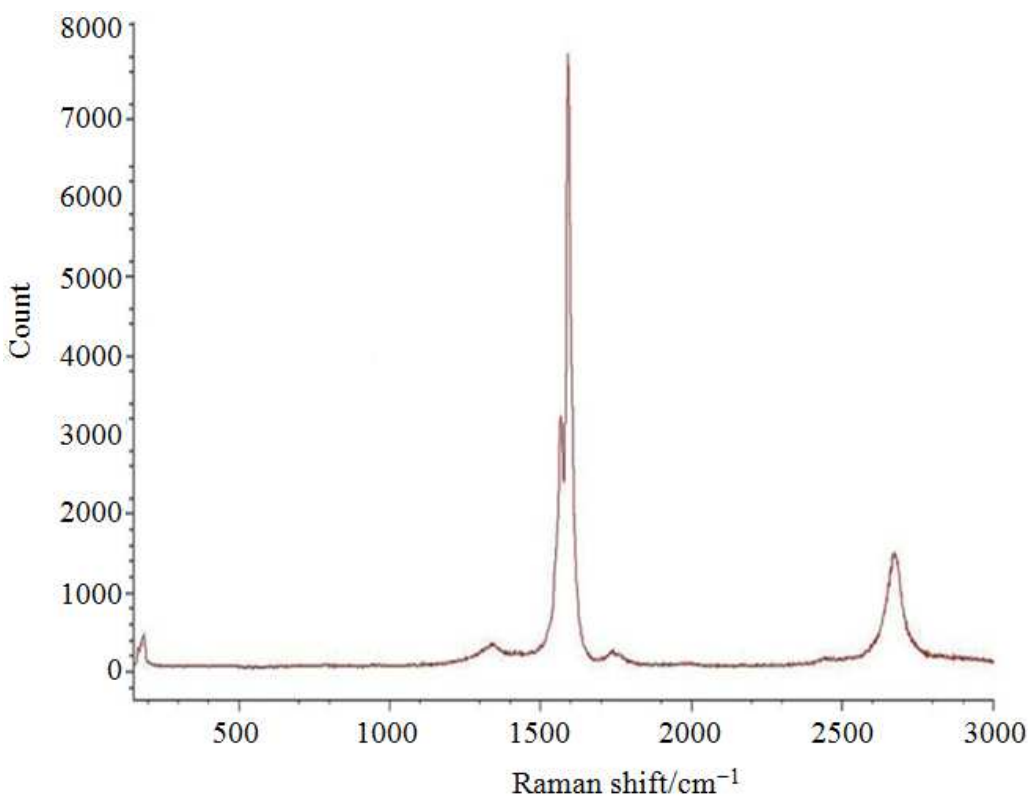

Fig. 2. Raman spectroscopy $(\lambda=514 \mathrm{~nm})$ 


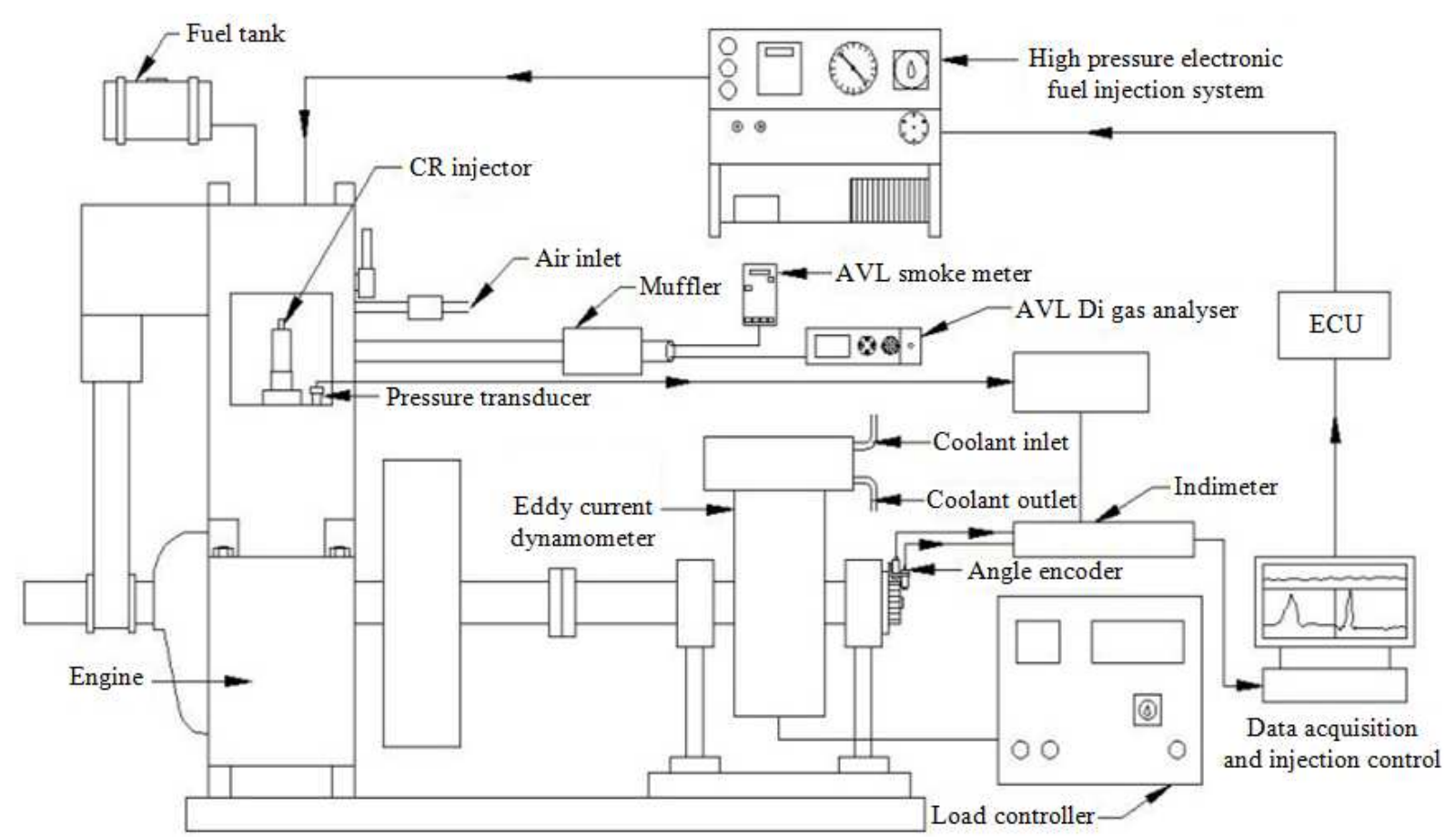

Fig. 3. Experimental setup

Table 1. Properties of diesel - CMNT blend samples

\begin{tabular}{lllll}
\hline Description & $\begin{array}{l}\text { Density @ } 15^{\circ} \mathrm{C} \\
(\mathrm{kg} / \mathrm{m} 3)\end{array}$ & $\begin{array}{l}\text { Flash } \\
\text { Point }\left({ }^{\circ} \mathrm{C}\right)\end{array}$ & $\begin{array}{l}\text { Calorific } \\
\text { value, }(\mathrm{kJ} / \mathrm{kg})\end{array}$ & $\begin{array}{l}\text { Cetane } \\
\text { number }\end{array}$ \\
\hline Diesel fuel & 815 & 58 & 42,000 & 47.0 \\
Diesel fuel with 25 ppm CMNT & 819 & 61 & 42426 & 48.4 \\
Diesel fuel with 50 ppm CMNT & 823 & 65 & 42731 & 49.6 \\
\hline
\end{tabular}

Table 2. Engine specification

\begin{tabular}{lll}
\hline Type & $:$ & Vertical, water cooled, four stroke \\
\hline Number of cylinders & $:$ & One \\
Bore & $:$ & $80 \mathrm{~mm}$ \\
Stroke & $:$ & $110 \mathrm{~mm}$ \\
Compression ratio & $:$ & $17.5: 1$ \\
Maximum power & $:$ & $5.2 \mathrm{~kW}$ \\
Speed & $:$ & $1500 \mathrm{rev} / \mathrm{min}$ \\
Dynamometer & $:$ & Eddy current \\
Injection timing & $:$ & $23(\mathrm{before} T \mathrm{TC})$ \\
Injection pressure & $:$ & $220 \mathrm{kgf} / \mathrm{cm}^{2}$ \\
\hline
\end{tabular}

The fuel flow rate is obtained on the gravimetric basis and the airflow rate is obtained on the volumetric basis. Eddy current dynamometer was used for loading the engine. The AVL smoke meter is used to measure the smoke density. AVL five-gas analyzer is used to measure $\mathrm{HC}, \mathrm{CO}$ and $\mathrm{NO}_{x}$ emissions. A burette is used to measure the fuel consumption for a specified time interval. During this interval of time, how much fuel the engine consumes is measured, with the help of a stopwatch. The experimental setup is indicated in Fig. 3.

\section{Results and Discussion}

The operation of the engine was found to be very smooth throughout the rated load, without any operational problems for the carbon multiwalled nanotubes blended diesel fuel. In the present section, based on the combustion data, cylinder pressure and heat release rate are plotted against crank angle. The performance attributes such as brake thermal efficiency, specific fuel consumption and the emission characteristics such as $\mathrm{NO}_{x}, \mathrm{CO}, \mathrm{HC}$ and smoke density are plotted against brake power.

\section{Engine Performance}

\section{Specific Fuel Consumption (SFC)}

Figure 4 shows the variation of specific fuel consumption with brake power. It was observed that the SFC of the CMNT-blended diesel is lower than that of neat diesel for all loads because of improved atomization and better mixing process at higher injection pressure. The decrease in SFC can be due to the positive effects of nanoparticles on physical 
properties of the fuel and reduction of ignition delay time (Karthikeyan et al., 2014). Corresponding to brake power, the specific fuel consumption decreases with an increase in the dosing level of CMNT. The average decrease in SFC compared to diesel is found as $0.25 \%$ for CMNT25 and $0.46 \%$ for CMNT50.

\section{Brake Thermal Efficiency (BTE)}

Figure 5 illustrates the variation of the brake thermal efficiency with brake power. The results show that the brake thermal efficiency of the diesel engine is improved by the addition of CMNT in diesel fuel. In general, the nanosized particles possess a high surface area and reactive surfaces that contribute to higher chemical reactivity to act as a potential catalyst (Tyagi et al., 2008; Aalam et al., 2015). It has been observed that the improvement in the brake thermal efficiency increases with the dosing level of carbon multiwalled nanotubes. A maximum increase of $2.5 \%$ in the brake thermal efficiency was obtained when the dosing level of CMNT is $50 \mathrm{ppm}$.

\section{Emission Parameters}

\section{Oxides of Nitrogen $\left(N O_{x}\right)$ Emission}

Observation has been made on the level of the $\mathrm{NO}_{x}$ emissions from diesel, in the purest form and in the modified form. The $\mathrm{NO}_{x}$ emissions were found to be generally decreased with the addition of carbon multiwalled nanotubes to diesel, as shown in Fig. 6. $\mathrm{NO}_{x}$ emissions of diesel without the addition of carbon multiwalled nanotubes were $870 \mathrm{ppm}$ and after addition of carbon multiwalled nanotubes it has been decreased.
At the dosage of $25 \mathrm{ppm}$ carbon multiwalled nanotubes, $\mathrm{NO}_{x}$ emissions will be $740 \mathrm{ppm}$ and for dosage of 50 ppm carbon multiwalled nanotubes, $\mathrm{NO}_{x}$ emissions will be $630 \mathrm{ppm}$. It is observed that the presence of the carbon multiwalled nanotubes in the diesel blend decreases the nitrogen oxide emissions.

\section{Carbon Monoxide (CO) Emission}

Figure 7 shows the influence of the carbon multiwalled nanotubes addition with biodiesel on carbon monoxide emissions. If the combustion is incomplete due to shortage of oxygen or low gas temperature, $\mathrm{CO}$ will be formed. Carbon multiwalled nanotubes act as an oxygen reduction catalyst. Hence, there was a slight rise in carbon monoxide (CO) emissions for carbon multiwalled nanotubes blended diesel. At the full load, the CO emissions for diesel were $0.49 \%$ (by volume) and 0.67 and $0.75 \%$ (by volume) for CMNT25 and CMNT50, respectively.

\section{Hydrocarbon (HC) Emission}

The variation of hydrocarbon emission with brake power is shown in Fig. 8. The addition of carbon multiwalled nanotubes slightly increases the $\mathrm{HC}$ emission when compared with neat diesel. Carbon multiwalled nanotubes are an oxygen reduction catalyst that increases the carbon combustion activation temperature and thus decrease hydrocarbon oxidation. From this figure, it is seen that the $\mathrm{HC}$ emission increased with the increase of CMNT dosing level with diesel. HC emission for CMNT25 was 120 and 135 ppm for CMNT50 blend, respectively.

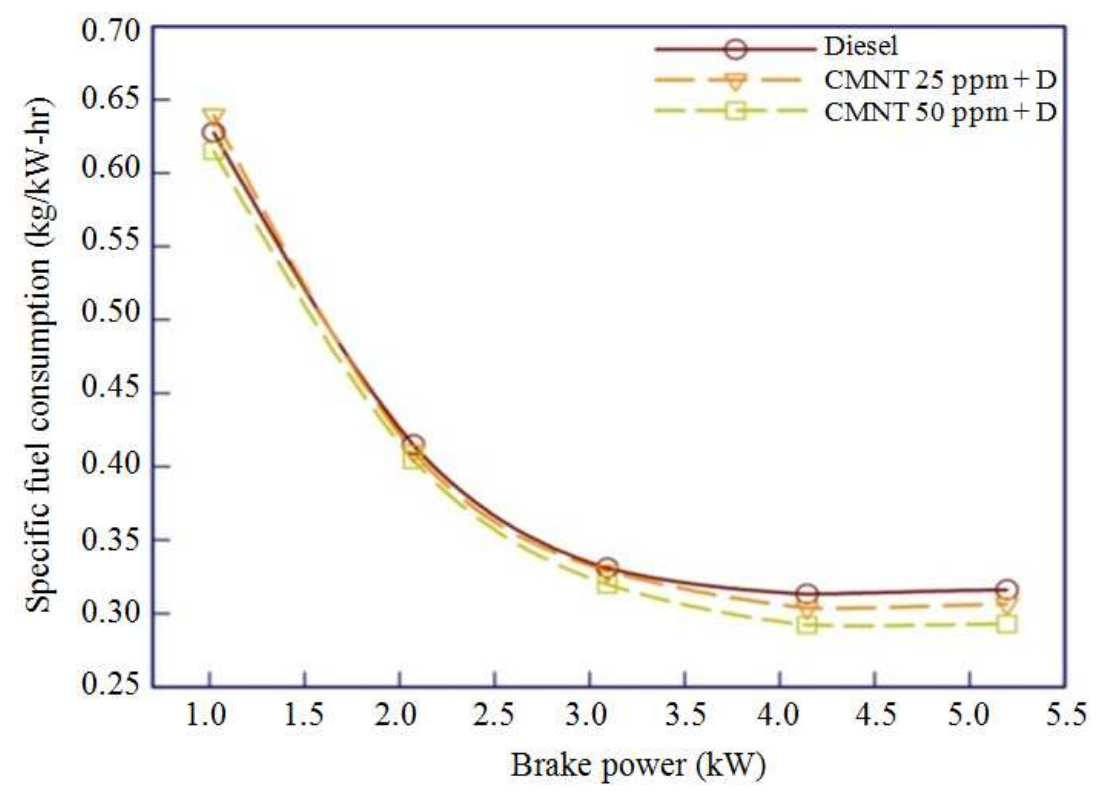

Fig. 4. Specific fuel consumption against brake power 


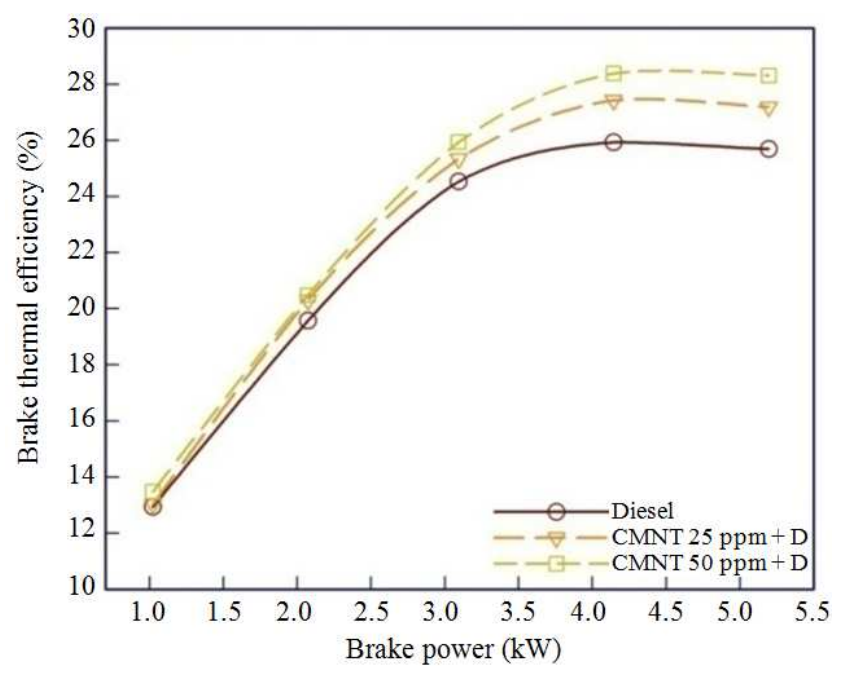

Fig. 5. Brake thermal efficiency against brake power

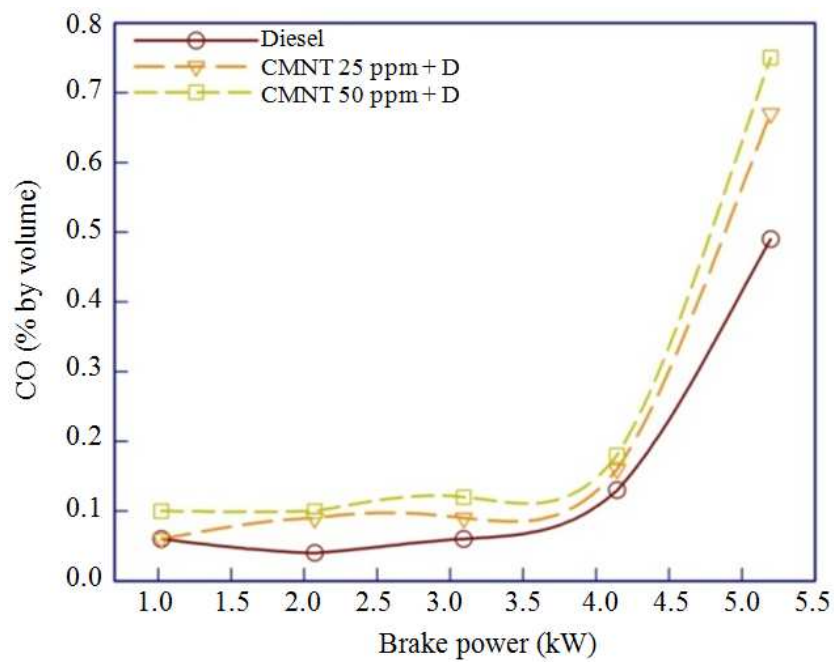

Fig. 6. Oxides of nitrogen against brake power

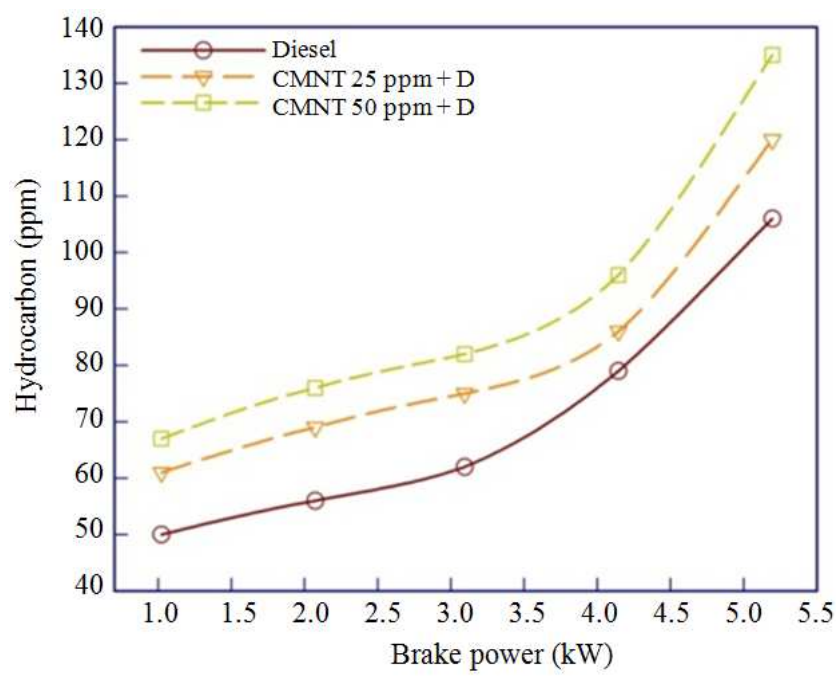

Fig. 7. CO against brake power 


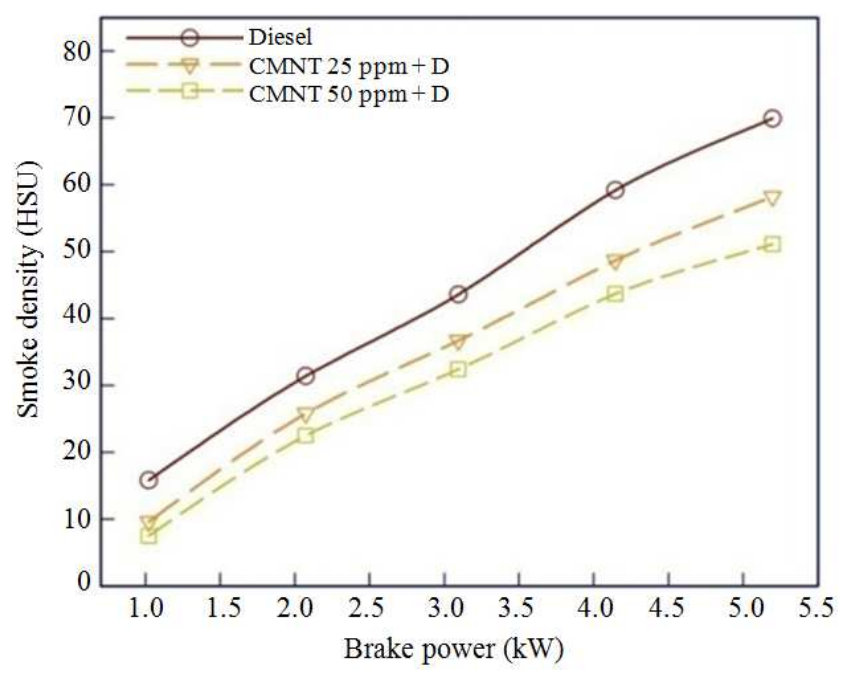

Fig. 8. Hydrocarbon against brake power

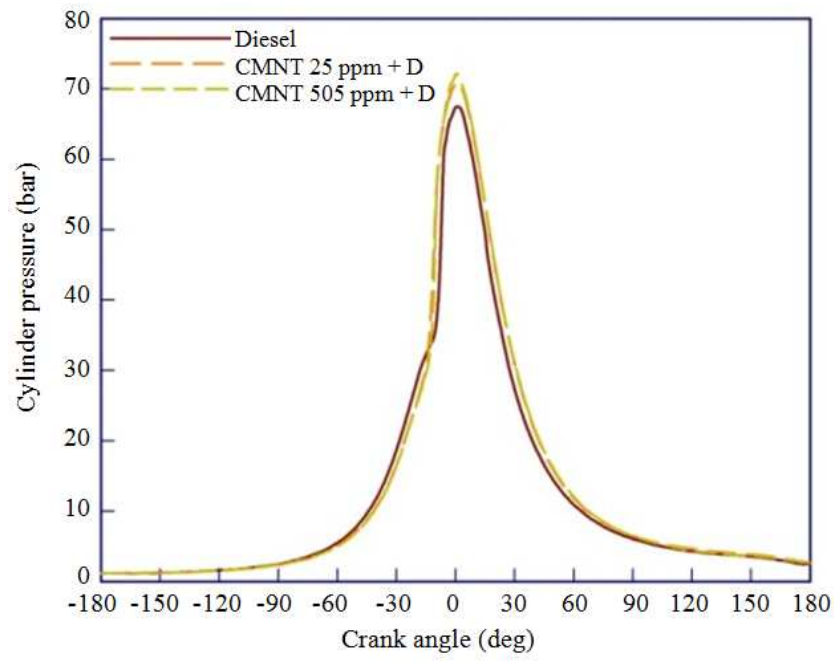

Fig. 9. Smoke density against brake power

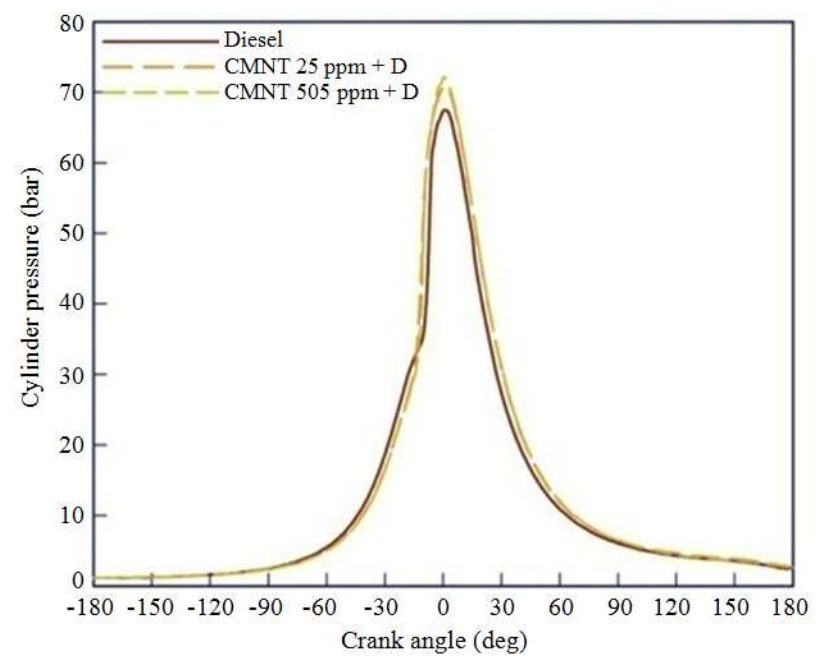

Fig. 10. Cylinder pressure against crank angle 


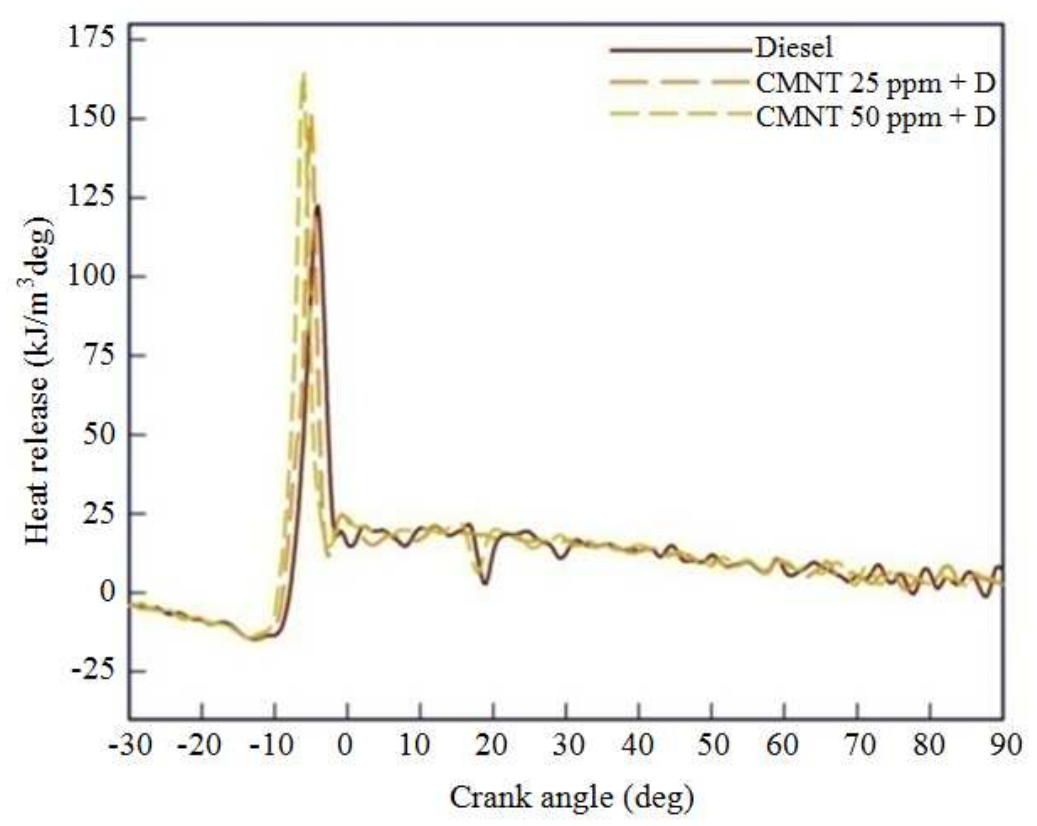

Fig. 11. Heat release rate against crank angle

\section{Smoke Density}

Figure 9 shows the variation of smoke density with brake power for diesel and modified diesel. However, reduced smoke opacity is observed in the case of CMNT-diesel blended fuels. The smoke density of diesel was decreased with the addition of CMNT by about $10-15 \%$, especially at full load. This could be attributed to shorter ignition delay characteristics of CMNT-diesel-blended fuels. It was also observed that the reduction in the smoke density increases with the increase in the concentration of CMNT.

\section{Combustion Characteristics}

Figure 10 shows the variation of cylinder pressure with crank angle for diesel and modified diesel with different dosing levels of the CMNT at different engine operating conditions. Addition of nanoparticles tends to reduce the ignition delay (Sadik Basha and Anand, 2011). From the figure, it is seen that the cylinder pressure for two different dosing levels of CMNT25 and CMNT50 was 66.117 and 69.946 bar, respectively. It is clear that the cylinder pressure slightly decreased with the increase in CMNT in biodiesel.

The variation of heat release rate with crank angle is shown in Fig. 11. The addition of nanoparticles enhances higher carbon combustion activation and hence promotes complete combustion (Sajith et al., 2010). The nanoparticle blended fuels showed accelerated combustion due to the shortened ignition delay. Due to shortened ignition delay, the degree of fuel-air mixing and uniform burning could have improved (Bahgat et al., 2011). The results show that the heat release rate was found to be generally decreased with the addition of CMNT to diesel. This is due to premixed and uncontrolled combustion phase. The amount of heat release rate is $124.727,149.818$ and $164.928 \mathrm{~kJ} / \mathrm{m}^{3} \mathrm{deg}$ for diesel, CMNT25 and CMNT50, respectively.

\section{Conclusion}

From the experiments carried out on the CRDI system assisted diesel engine fuelled with diesel and carbon multiwalled nanotubes blended diesel, the following conclusions can be drawn:

- Good improvement in brake thermal efficiency was observed with carbon multiwalled nanotubes blended diesel at optimized operating conditions

- With the addition of carbon multiwalled nanotubes to diesel fuel, the level of harmful pollutants in the exhaust gases, such as $\mathrm{NO}_{x}$ and smoke, was significantly reduced when compared to that in neat diesel. At the dosage of $25 \mathrm{ppm}$ CMNT, $\mathrm{NO}_{x}$ emissions will be $740 \mathrm{ppm}$ and for dosage of $50 \mathrm{ppm}$ CMNT, $\mathrm{NO}_{x}$ emissions will be $630 \mathrm{ppm}$. The smoke density of diesel was decreased on addition of carbon multiwalled nanotubes by about $10-16 \%$, especially at full load 
- Carbon multiwalled nanotubes blended diesel fuel showed higher cylinder gas pressure and heat release rate at optimized operating conditions

Hence, CMNT is efficient in improving performance and reducing the exhaust harmful pollutants from the diesel engine.

\section{Funding Information}

The authors have no support or funding to report.

\section{Author's Contributions}

This research work is carried out by the first author C. Syed Aalam and guided by the second author Dr. C.G. Saravanan. M. Kannan helped in conducting the experimental work.

\section{Ethics}

This article is original and contains unpublishedmaterial. The corresponding author confirms that all ofthe other authors have read and approved the manuscriptand no ethical issues involved.

\section{References}

Aalam, C.S., C.G. Saravanan and M. Kannan, 2015. Experimental investigations on a CRDI system assisted diesel engine fuelled with aluminium oxide nanoparticles blended biodiesel. Alexandria Eng. J.

DOI: 10.1016/j.aej.2015.04.009

Arul Mozhi, S.V., R.B. Anand and M. Udayakumar, 2009. Effects of cerium oxide nanoparticle addition in diesel and diesel-biodiesel-ethanol blends on the performance and emission characteristics of a CI engine. J. Eng. Applied Sci., 4: 1-6.

Bahgat, M., A.A. Farghali, W.M.A. El Rouby and M.H. Khedr, 2011. Synthesis and modification of MultiWalled Carbon Nano-Tubes (MWCNTs) for water treatment applications. J. Analytical Applied Pyrolysis, 92: 307-313.

DOI: 10.1016/j.jaap.2011.07.002

Basha, J.S. and R.B. Anand, 2014. Performance, emission and combustion characteristics of a diesel engine using carbon nanotubes blended jatropha methyl ester emulsions. Alexandra Eng. J., 53: 259-273. DOI: 10.1016/j.aej.2014.04.001

Cao, A., C. Xu, J. Liang, D. Wu and B. Wei, 2001. Xray diffraction characterization on the alignment degree of carbon nanotubes. Chem. Phys. Lett., 344: 13-17. DOI: 10.1016/S0009-2614(01)00671-6
Dresselhaus, M.S., G. Dresselhaus, R. Saito and A. Jorio, 2005. Raman spectroscopy of carbon nanotubes. Phys. Reports, 409: 47-99. DOI: $10.1016 /$ j.physrep.2004.10.006

Fangsuwannarak, K. and K. Triratanasirichai, 2013. Improvements of palm biodiesel properties by using nano-TiO2 additive, exhaust emission and engine performance. Proceedings of the International Conference Bucharest, Sept. 12-13, Romania.

Hirscher, M., M. Becher, M. Haluska, A. Quintel and V. Skakalova et al., 2002. Hydrogen storage in carbon nanostructures. J. Alloys Compounds, 330-332: 654-8. DOI: 10.1016/S0925-8388(01)01643-7

Karthikeyan, S., A. Elango and A. Prathima, 2014. Diesel engine performance and emission analysis using oil methyl ester with the nano sized zinc oxide particles. Ind. J. Sci. Indus. Res., 21: 83-87.

Kumar, A. and S. Sharma, 2014. Role of emulsion and nanotechnology in alternative fuel for compression ignition engine: Review. Int. J. Curr. Eng. Technol.

Li, L., F. Li, C. Liu and H.M. Cheng, 2005. Synthesis and characterization of double-walled carbon nanotubes from multi-walled carbon nanotubes by hydrogen-arc discharge. Carbon, 43: 623-629.

DOI: 10.1016/j.carbon.2004.10.028

Orinakova, R. and A. Orinak, 2011. Recent applications of carbon nanotubes in hydrogen production and storage. Fuel, 90: 3123-3140. DOI: $10.1016 /$ j.fuel.2011.06.051

Paradise, M. and T. Goswami, 2007. Carbon nanotubes-production and industrial applications. Mater. Design, 28: 1477-1489.

DOI: 10.1016/j.matdes.2006.03.008

Piriyawong, V., V. Thongpool, P. Asanith and P. Limsuwan, 2012. Preparation and characterization of alumina nanoparticles in deionized water using laser ablation technique. J. Nanomaterials, 2012: 819403-819408.

Popov, V.N., 2004. Carbon nanotubes: Properties and application. Mater. Sci. Eng. R, 43: 61-102. DOI: $10.1016 /$ j.mser.2003.10.001

Popov, V.N., 2004. Carbon nanotubes: Properties and application. Mater. Sci. Eng. R, 43: 61-102. DOI: 10.1016/j.mser.2003.10.001

Ruoff, R.S. and D.C. Lorents, 1995. Mechanical and thermal properties of carbon nanotubes. Carbon, 33: 925-30. DOI: 10.1016/0008-6223(95)00021-5

Sadik Basha, J. and R.B. Anand, 2011. Role of nanoadditive blended biodiesel emulsion fuel on the working characteristics of a diesel engine. J. Renew. Sust. Energy. DOI: 10.1063/1.3575169 
Sajith, V., C.B. Sobhan and G.P. Peterson, 2010. Experimental investigations on the effects of cerium oxide nanoparticle fuel additives on biodiesel. Adv. Mech. Eng., 2010: 581407-581412.

Tajudeen, S. and R. Velraj, 2014. Nano additives: Enhancement of combustion and performance characteristics of a CI diesel engine. Int. J. Applied Environ. Sci., 9: 1727-1741.

Tyagi, H., P.E. Phelan, R. Prasher, R. Peck and T. Lee et al., 2008. Increased hot-plate ignition probability for nanoparticle-laden diesel fuel. Nano Lett.., 8: 1410-1416. DOI: $10.1021 / \mathrm{nl} 080277 \mathrm{~d}$

\section{Nomenclature}

bmep

SFC

$\mathrm{BP}$

$\mathrm{CO}$

$\mathrm{HC}$

$\mathrm{NO}$

CRDI

CMNT25

CMNT50

rpm
Brake mean effective pressure, $\mathrm{MPa}$ Specific fuel consumption, $\mathrm{kg} / \mathrm{kW} . \mathrm{h}$ Brake power

Carbon monoxide, \%

Hydrocarbon, ppm Nitrogen oxide, ppm Common rail direct injection CMNT of 25ppm blended with diesel CMNT of 50ppm blended with diesel Revolution per minute 